\title{
A Study on Interest Conflicts of Civil Servants from Multidisciplinary Perspectives
}

\author{
Xuefeng Lv \\ Hubei Administration College, The research base of the party school of the research center of the socialist \\ theory system of socialism with Chinese characteristics in hubei province, Wuhan, 430000, China
}

Keywords: Civil servants; interest conflicts; multidisciplinary perspectives

\begin{abstract}
The interest conflicts is common phenomenon in human society. The interest conflicts of civil servants is a common problem of administrative ethics, and a new perspective in international anti-corruption field. This paper analyzes the interest conflicts of civil servants from the perspective of public administration, sociology and management, so as to have a more comprehensive understanding of interest conflicts of civil servants, and solve this problem more advisably.
\end{abstract}

\section{Introduction}

In eighteenth century, the French materialist philosopher Helvetius systematically discussed question of interests. In his book "De l'esprit", he made a comprehensive study of the nature, content, characteristics and functions of interests, and emphasized that "interest is our only motive force" and pointed out that "individuals always obey their understanding correctly or incorrectly.". Therefore, by making good laws and pursuing personal happiness according to their tendency, people could be led to public happiness naturally, which can make personal interests and public interests closely linked and make citizens become moral. According to Marx's argument, the formation of human interests is a logical process from human needs to human labor and then to social relations. Human interests originate from their needs, human production is the intermediary between human needs and needs, and human needs are constrained by the level of productive forces. That is to say, in order to make production, individuals would have a certain relationship with others; only in these social communications and social relationships, people would have their relationships with nature, so that the production is appeared. The different needs of people, expressed through social relationships, are interests. The need is the source and basis of interests, and the interest is the social reaction and form of need. In the real world, individuals have millions of needs, which determine the richness, diversity and complexity of interests, which make different interests inevitably link and interact with each other, resulting in interest conflicts and opposition. Interest conflicts could be divided into three types. The first category is that Conflicts between different interests within an individual, such as the immediate and long-term interests of an individual. The second type is that conflicts between different stakeholders at the same level, such as conflicts among individuals classes. The last type is that conflicts among stakeholders at different levels, such as the conflict between individual interests and the collective interests. In this paper, the interest conflicts of civil servants refers to the interference between personal interests and public interests.

The interest conflicts prevention is an important issue in the field of international clean government construction. Many scholars regard interest conflicts as the primary negative impact in a clean government construction. In order to prevent interest conflicts, Canada, the United States, Japan and other countries have promulgated several perfect policies and regulations since 1980s, and some countries even put the ethical requirements to prevent interest conflicts into the constitution. In the third Plenary Session of the 18th CPC Central Committee, we pointed out that it is necessary to strengthen institutional innovation protection of anti-corruption so as to prevent and control corruption risks and interest conflicts. 


\section{The Perspective of Public Administration}

The theory of public choice is based on the economic person assumption. According to this assumption, person is rational and pursues the maximization of personal interests and benefits, whose activities are driven and directed by individual interests. The theory holds that individual shows the same feature in the political sphere. Therefore, a country or government composed of individuals should not be regarded as serving the public interests. Public organizations are not only the departments, existing for public interests, but also are areas where individuals try to achieve personal interests through the development of their career. The goal of administrative personnel is not necessarily the public interest, but also includes the motivation of obtaining personal benefits, such as salary, reputation and promotion. From this point of view, the personal interests of civil servants are not necessarily consistent with the pursuit of public interests, so interest conflicts of civil servants appears.

The current policies of interest conflicts adopted by most of the international communities include prohibition, avoidance, restriction, openness and divestiture. In addition to the divestiture, China has corresponding contents in the other four kinds of interest conflicts policies. However, the current policies are not perfect, and the implementation effect is not ideal. At first, these policies are not perfect. For instance, the avoidance is mainly concentrated on the leadership position, but the non leadership position is not clearly defined. There are some problems in openness policies, such as limited property declaration, incomplete declaration time and non disclosure of declaration procedure. In addition, the level of these polices is low. At present, most of the policies appear in the form of the internal documents of the party and the government, which are not risen to the height of the law. Therefore, the binding force and deterrence is not enough to truly play a role in preventing interest conflicts. China should stipulate and coordinate the behavior of civil servants' interest conflicts as soon as possible, through enhancing the authority, rigor and operability of the system, and building a solid policy system.

\section{The Perspective of Sociology}

From the sociological point of view, the interest conflicts of civil servants can be seen as the role conflict of civil servants. In the sociology, the role refers to the rights, obligations, norms and behavior patterns that are consistent with individual's social status and identity, which is the expectation of individual's behavior in a specific position, and constitutes the basis of social groups and social organizations. A role is always associated with certain norms of behavior patterns, such as teachers should set example for the students, public administrators should serve the public. No one can bear only one kind of social role, but bear many social roles, which are linked to more social roles and form the role sets. The role sets contain two kinds of situations. The first situation is that a variety of social roles are embedded into one person, and they reflect a personal relationship. Another is that a group of interdependent roles that embody a relationship among different people. Because a person has to play a variety of roles, sometimes these different role expectations will occur contradictions, opposition or conflict in the role play process, and this phenomenon is called role conflicts. The conflicts between relative roles of different people are often called "role conflicts" which are caused by the the opposition of role interests, the difference of role expectations and the lack of normative action. The conflict between the roles of civil servants is often manifested as the contradiction and divergence between the civil servants at the lower or same level. The interest conflicts of civil servants are mainly caused by role conflicts. The internal conflict of civil servants refers to the contradictions and conflicts among the civil servants in the process of public affairs management, because they play multiple roles at the same time. It usually includes the following situations. At first is that a person takes on various social roles, and at the same time some requirements are put forward to him, which makes him difficult to conduct so that there is a conflict within the roles. Secondly, there are conflicts among roles that a person assumes, and their norms of behavior are incompatible. At last, there are conflicts within a single role sometimes. Role conflicts would hinder and destroy people's normal order of life, and the common 
solution is that a person who takes on too many roles should reduce his excessive part-time jobs so that he can devote his energies to the most important position. In addition, we should design the role scientifically and reasonably, and make the role as single as possible in view of role conflicts caused by the inconsistency of role specification. For civil servants, we should standardize the duties and privileges of all levels of civil servants, configure the powers and functions of the institutions scientifically, and clarify the responsibilities and tasks of the posts. At last, people need to use their values to do role selection when the role conflicts involve social values. In particular, when individual interests conflict with public interests, different moral abilities and values determine the positions and views of individual considerations directly, and affect the choice of civil servants. Therefore, the quality of public officials should be improved through selection, training and other methods. In addition, strengthening ideological and political work, as well as improving awareness, are also important measures to prevent role conflicts. Under this circumstance, it is necessary to formulate "civil servant ethics law" as soon as possible, to provide clear moral standards and guidelines for public officials, and to internalize professional values into administrative staff's code of conduct. Just like Macintyre said: No matter how comprehensive the system is, if people do not have good morality, it is impossible to have any effect on human behavior. Only those who have the virtue of justice may know how to use the laws.

\section{The Perspective of Management}

Cognitive dissonance theory is used to explain the relationship between attitude and behavior, which refers to the disharmony and inconsistency between different attitudes. This theory holds that any form of inconsistency can make people uncomfortable, so individuals will try to reduce this inconsistency. When these inconsistencies occur, individuals take measures to keep them consistent. Common methods include changing attitudes, changing behaviors and finding reasons for this inconsistency. The theory argues that the desire to reduce dissonance is determined by the following three factors. The first factor is the importance of dissonance. Furthermore, the second factor is the extent to which individuals believe themselves to be controlled by other factors. The last one is The benefits of individual when involving dissonance.

If reasons of dissonance are relatively less important, the pressure to adjust this imbalance is relatively small. When a person in dissonance feels be controlled by other factors, it also affects his response to the dissonance. The existence of relevant provisions of interest conflicts of civil servants can not restraint the behavior of civil servants, so some external power need to be adopted to control the interest conflicts. Therefore, we should promote the public decision-making, open management, open service, open results, and let power operate under the sun. At the same time, a variety of supervision mechanisms should be improved so that the behavior of public officials can be supervised easily. Finally, rational individuals tend to carry out cost-benefit analysis when making decisions. From this point of view, it is necessary to increase the cost of civil servants' illegal activities, weaken their motivation of illegal activities, and make them act in accordance with public interests.

\section{Summary}

The interest conflicts of civil servants are common administrative ethical problems, and also new perspectives for the clean governance construction. From the above analysis, not only relevant laws and regulations should to be improved, civil service posts and power should be set up rationally, the quality of civil servants and public ethical spirit should be cultivated, but also the external supervision mechanism should be improved as well, so as to make the civil servants make public interest behavior.

\section{References}

[1] Xiao Maosheng. Responsibility Conflict and Administration Ethics Decision-making of Public 
Servant [J]. Chinese Public Administration, 2006, (05): 42-44.

[2] Zhuang Deshui. The current situation and Development Countermeasures of Interest Conflict Policies of Civil Servants in China [C]. Seminar on the administrative system of socialism with Chinese characteristics and the Chinese society of administration, 2010.

[3] Zhang Xiaozhen. Research on the Interest Conflicts of Chinese Civil Servants in Business [D]. Hunan University, 2010.

[4] Long Taijiang \& Wang Kezhang. On the Legislation on Civil Servants Conflict of Interests [J]. Journal of Guangzhou University (Social Science Edition), 2012, 11(01): 10-15.

[5] Long Taijiang \& Bo Lanlan. Clash of Interests after Civil Servant's Resignation [J]. Exploration and Free Views, 2007, (06): 38-41.

[6] Zhou Mengke, Wen Zhiqiang. Analysis of Preventing Civil Servants' Conflict of Interest: Harm and Resolution [J]. The Guide of Science \& Education.

[7] He Diankui, Wang Anli. On the Autonomous Characteristics of Colony Benefit Conflicts and the Choice of Countermeasures in Modern China [J]. The Journal of Yunnan Administration College, 2010, 12(03): 56-59.

[8] Zhang Naixin. The Autonomy of Group Interest Conflicts in Contemporary China and the Choice of Solutions [J], Journal of Beijing Administrative College. 